\title{
Prevalence, causes, magnitude and risk factors of visual impairment and blindness in Sri Lanka
}

\author{
C Banagala ${ }^{1}$, C Gilbert ${ }^{2}$, G V S Murthy ${ }^{2,3}$, E Schmidt $^{4}$, P G Mahipala ${ }^{5}$, K Edussuriya $^{6}$, K M K Gamage $^{1}$, \\ RP Kumara ${ }^{7}$, S A H K Wimalarathne ${ }^{7}$ on behalf of the National Sri Lanka Steering Committee and \\ National Blindness, Visual Impairment and Disability Survey Team ${ }^{8}$
}

\begin{abstract}
Introduction There is paucity of data on the epidemiology of visual impairment in Sri Lanka.

Objectives Estimate the prevalence and determine causes and risk factors of visual impairment among adults aged $\geq 40$ years in Sri Lanka.

Methods Multistage, stratified, cluster random sampling was used to select a nationally representative sample aged 40 years. All participants underwent vision testing, autorefraction and a basic eye examination. Participants with a presenting acuity of $<6 / 12$ in either eye underwent detailed eye examination, assessment of bestcorrected acuity if required, and a cause of visual loss assigned.
\end{abstract}

Results 5,779 of those enumerated $(6,713)$ were examined (response rate $86.1 \%$ ). The prevalence of blindness was $1.7 \%$ (95\% confidence interval [Cl]: 1.3$1.99 \%)$ and low vision was $17 \%(95 \% \mathrm{Cl}$ : $16.0-18.0 \%)$. Cataract $(66.7 \%)$ and uncorrected refractive errors $(12.5 \%)$ were the commonest causes of blindness. Uncorrected refractive errors (62.4\%) and cataract $(24.2 \%)$ were the commonest causes of low vision. Blindness was significantly higher in older age groups (OR 132.4: $95 \% \mathrm{Cl} 11.7-149.3$ ), those residing in the North Central (OR-12.5), North (OR-12.0), North West (OR-7.3), Eastern (OR-6.7), Western (OR-5.3) and Uva provinces (OR-5.3) compared to the Southern, and in those educated up to and including secondary school (OR 2.3: 95\% Cl 1.5- 3.17). Gender and socio-economic status were not significant after adjusting.

Conclusions The prevalence of blindness in Sri Lanka is lower than in other South Asian countries and most causes are avoidable. Access to eye care needs to improve amongst the aged, those less educated and those in provinces with higher blindness risk.

Ceylon Medical Journal 2018; 63 (S2): s10-s17

DOI: http://doi.org/10.4038/cmj.v63i5.8736

\section{Introduction}

The World Health Organization (WHO) estimated 285 million visually impaired persons globally including 39 million blind and 246 million with low vision ${ }^{1}$. A subsequent systematic review estimated the number of blind in 2010 to be 32.4 million, and a further 191 million as moderately or severely visually impaired (MSVI/low vision $)^{2}$. This showed that there was a $20 \%$ decrease in blindness prevalence over the period 1990-2010. The study provided estimates for 21 sub-regions worldwide but Sri Lanka did not contribute to the estimates. The only evidence available from Sri Lanka is from the Central province where among adults aged $\geq 40$ years, the prevalence of blindness, based on best-corrected visual acuity(BCVA), as $1.1 \%{ }^{3}$.

Sri Lanka has a population of 21.27 million (2013) and is one of the fastest ageing countries in South Asia ${ }^{4}$. The rapid demographic transition coupled with systematic improvement of public and primary health care has resulted in significant changes in the pattern of disease from communicable to non-communicable diseases ${ }^{5}$.

${ }^{1}$ College of Ophthalmologists of Sri Lanka, Colombo, Sri Lanka, ${ }^{2}$ Department of Clinical Research, London School of Hygiene and Tropical Medicine, London, United Kingdom. ${ }^{3}$ Indian Institute of Public Health Hyderabad, Public Health Foundation of India, Hyderabad, India, ${ }^{4}$ Sightsavers, Haywards Health, United Kingdom, ${ }^{5}$ Director General Health Services, Ministry of Health, Sri Lanka, ${ }^{6}$ Department of Ophthalmology, General Hospital, Kandy, Sri Lanka, ${ }^{7}$ Survey Ophthalmologists, National Blindness, Visual Impairment and Disability Survey, Sri Lanka, ${ }^{8}$ In addition to the above, other members of the Sri Lanka National Blindness, Visual Impairment and Disability Survey Team: Asela Pradeep Abeydeera, Ahamed Jeza, Saman Senanayake, Sunil Fernando, Lakmini Dissanayake, Nirmi Vitharana, Nimal Edirisinghe, Sunil Settinayake, Attapathu AH, Priyangani MD, Bandara KRTC, Chamin Rathnayake, Y G Upali Jayarathne, Hira Ballabh Hira Ballabh Pant, Souvik Bandhopadhyaya, Mahesh Dorairaj, Sandeep Bhuttan.

Correspondence: GVSM, e-mail: <Gvs.Murthy@lshtm.ac.uk>. Received 19 February 2018 and revised version accepted 23 June 2018. 
The WHO Global Action Plan (2014-2019) for eye health urges member States to obtain population data on the prevalence and causes of visual impairment to plan services based on the need in the population ${ }^{6}$. In response to this call, the VISION 2020 National Program for the Prevention and Control of Avoidable Blindness in Sri Lanka initiated a population-based national survey to estimate the prevalence, magnitude and major causes of blindness and visual impairment in adults aged $\geq 40$ years nationally and by province, rural/urban residence, socio-economic status and demographic variables. The survey was undertaken in collaboration with the London School of Hygiene \& Tropical Medicine (LSHTM) and the Indian Institute of Public Health, Hyderabad, India. A Survey Steering Committee was convened to oversee all aspects of the survey.

\section{Methods}

A detailed description of the survey methodology is provided earlier in this issue and a summary is included here. The sample size was 6,800 persons aged $\geq 40$ years in 68 clusters.

Distance presenting visual acuity (PVA) (i.e. with distance correction if usually worn) for each eye was measured by an optometrist using an 'Early Treatment for Diabetic Retinopathy Study' (EDTRS) logarithm of minimum angle of acuity (logMAR) tumbling E chart at four meters, and at one meter if required using a $+0.75 \mathrm{D}$ sphere in a trial frame. If no optotypes could be seen by the eye at one meter, the eyes were assessed for the ability to count fingers, see hand movements or perceive light. All participants had autorefraction measurements taken by an optometrist (Topcon 8000 ). If the PVA was $<6 / 12$ in either eye, the autorefractor readings were used as the starting point to determine BCVA, after retinoscopy if required.

All participants were then examined by an ophthalmologist, who took an ocular history, and examined anterior and posterior segments through an un-dilated pupil at the slit lamp. If the PVA was $\geq 6 / 12$ in both eyes and no abnormality was detected no further examination was required. Participants who could not see $6 / 12$ in one or both eyes, or where basic eye examination revealed an abnormality, and all who had undergone cataract surgery were examined in detail by an ophthalmologist after dilating the pupils using a slit lamp and +90D fundus examination lens. Fundus images were taken of all these participants provided the media were clear enough. Participants unable to travel to the examination site were examined at home using a simplified protocol.

\section{Determining the cause of visual loss}

Causes of visual loss were assigned to all with a presenting VA of $<6 / 12$ in any eye, following the WHO algorithm designed for use in population based surveys [7]. All the disorders contributing to visual loss in each eye, and all relevant underlying causes were noted, and one main cause selected for each eye. If more than one cause was assigned to an eye, the following were preferentially selected, if applicable: primary causes (e.g., cataract secondary to uveitis, uveitis was selected), or the disorder contributing most to vision loss. If two conditions were judged to contribute equally to visual loss, the most readily treatable was selected. If none of the conditions were treatable, the most preventable was selected. Having established a main cause for each eye, a principal cause for the person was determined, by selecting the cause in the right or left eye, following a similar logic to that described above.

\section{Quality assurance}

All survey team members were trained for one week at the start of the survey by staff with expertise in large scale surveys from the LSHTM. Training was followed by a pilot study in two clusters. Inter-observer agreements studies were undertaken for VA measurement by the optometrists. Inter-observer agreement was assessed during training and the pilot. Senior ophthalmologists from the College of Ophthalmologists of Sri Lanka and Sightsavers India office monitored the data collection. All completed record sheets were checked for errors by the ophthalmologist in the field at the end of each day and by the Survey Coordinator in the office.

\section{Data management and analysis}

Data were entered by an experienced data officer into a customized database created in Microsoft Access, which had build-in range and consistency checks. Entries were cross-checked independently by a second data officer. Data cleaning and analysis were undertaken using STATA 13.0 (Stata Corp LP, Texas, USA) by a statistician at the Indian Institute of Public Health, Hyderabad, India.

Descriptive analysis and cross tabulations with calculation of Pearson's chi squared tests were performed. Prevalence estimates together with $95 \%$ confidence intervals were calculated. Further analysis was undertaken to explore risk factors for blindness using logistic regression with generalized equation to adjust for dependency in the data due to clustered sampling. All variables significant at 0.02 level in univariate analysis were included in the multivariate regression. All tests are two sided, and odd ratios (OR) and 95\% confidence intervals $(\mathrm{CI})$ are presented. To account for differential non-response, the blindness prevalence estimate was adjusted for age and gender. Multiple logistic regression analysis was performed to identify risk factors for blindness and to estimate adjusted Odds Ratios (OR).

\section{Definitions used}

\section{Visual impairment}

PVA in the better eye was used for all categories of visual impairment i.e. tested with distance correction if 
usually worn, or unaided. The following WHO categories were used: blindness $<3 / 60(<20 / 400)$ in the better eye; severe visual impairment $<6 / 60-3 / 60(<20 / 200-20 / 40)$ and moderate visual impairment $<6 / 18-6 / 60(<20 / 63-20 / 200)$ in the better eye. A further category was added, termed mild visual impairment i.e., $<6 / 12-6 / 18(<20 / 40-20 / 63)$ in the better eye. Low vision was defined as a presenting VA of $<6 / 18$ to $\leq 3 / 60(<20 / 63-20 / 400$ ) (WHO category) in the better eye. Peripheral visual field loss was not used in the definition of blindness, visual impairment or glaucoma as visual field assessment was not possible in the field setting.

\section{Socioeconomic status}

Information was collected on the possession of movable assets including television, computer, radio, cycle, motor cycle, car, refrigerator and air conditioner. A scoring system was devised based on the monetary value of each asset. Scores assigned to each asset were then summed to derive a family asset score, which were categorized into quartiles with the lowest quartile being defined as the middle number between the smallest number and the median of the data set. Participants were categorized using the family score as highest socioeconomic (SES) status: 1st quartile; upper middle $\left(2^{\text {nd }}\right.$ quartile); lower middle ( $3^{\text {rd }}$ quartile $)$ and lowest $\left(4^{\text {th }}\right.$ quartile $)$.

\section{Ethics}

The study protocol was approved by the institutional ethics committees of LSHTM, UK, the Faculty of Medicine, University of Colombo, Sri Lanka and the Indian Institute of Public Health, Hyderabad, India. All participants provided written informed consent.

\section{Results}

A total of 5,779/6,713 (86.1\%) adults were examined. Among the 934 not examined, 898 (94.1\%) were not in the cluster, vision could not be tested in $14(1.5 \%), 12(1.3 \%)$ refused examination, $12(1.3 \%)$ had an incomplete examination and $6(0.6 \%)$ were very sick and could not be examined. Response rates were highest in females. Response rates by province, literacy and place of residence were similar (Table 1).

\section{Prevalence}

Two thirds of participants $(3,899 ; 67.5 \%)$ had PVA $\geq 6 / 12$ in at least one eye and $13.6 \%$ (95\% confidence interval (CI) $12.7-14.5 \%$ ) were classified as having mild visual impairment $(<6 / 12-6 / 18)$. Ninety-six people were blind, giving a prevalence estimate of $1.7 \%$ (95\% CI 1.3-1.99\%), which reduced to $1.6 \%$ (95\% CI-1.3-2.0) after adjusting for age and sex (Table 2). The prevalence of low vision was $17.1 \%$ (95\% CI 16.0-18.0\%). Twenty-one individuals who were blind according to their presenting VA were no longer blind with best correction (Table 3 ).

\section{Risk factors for blindness}

On univariate analysis, the prevalence of blindness increased significantly with age, was higher in participants in households with lower asset scores, varied by Province from $0.3 \%$ (South Province) to $2.9 \%$ (Uva Province) and was significantly higher in the Tamil ethnic group (Table 4). After adjusting for socio demographic factors, increasing age, Province and lower literacy had significantly higher risk of blindness.

\section{Causes of blindness and visual impairment}

Cataract was the most common cause of blindness (66.7\%) followed by uncorrected refractive errors $(12.5 \%)$ (Table 5). Six participants $(6.3 \%)$ were blind following cataract surgery, mostly from treatable causes such as posterior capsule opacity or inadequately corrected pseudophakia. Retinal conditions were responsible for $7.3 \%$ of causes, with age related macular degeneration (ARMD) being the cause in $2.1 \%$. No participant was blind from diabetic retinopathy or corneal opacity and two $(2.1 \%)$ were blind from glaucoma.

Uncorrected refractive was the commonest cause of mild $(81.0 \%)$, moderate $(64.0 \%)$ and severe visual impairment $(46.7 \%)$ followed by lens opacities $(7.9 \%$; $22.9 \%$ and $36.7 \%$ respectively).

Using census data for 2014, we estimate that there are 1.42 million visually impaired or blind adults in Sri Lanka, $56 \%$ of whom are female. Among the visually impaired 126,250 are blind, $57 \%$ of whom are women.

\section{Discussion}

The prevalence of blindness in Sri Lanka is lower than in most other countries in South/ Southeast Asia [8-13], with cataract being responsible for two-thirds of blindness. This is higher than the global picture where $51 \%$ is due to cataract [1]. At least $80 \%$ of the causes are readily treatable with highly cost-effective interventions i.e. for cataract and uncorrected refractive errors. The data on the causes of blindness is like other countries in the region [2]. For example, the prevalence of blindness in Pakistan was $2.7 \%$ (2006) among adults aged $\geq 30$ years [10], while estimates from India range from $3.0 \%$ in those aged $\geq 40$ (in 2000) to $19.2 \%$ in those aged $\geq 50$ (in 2003) [8,9]. In Bangladesh ( $\geq 30$ years), the prevalence was $1.53 \%$ [13]. The variation in prevalence between countries can reflect true differences in prevalence because of differences in exposure to risk factors, variation in the age and sex structure of the population, and variation in access to and quality of eye care services. Surveys including younger participants will have a lower prevalence as most blindness occurs in individuals aged $\geq 50$ years [14]. Sampling technique, differences in definitions, methodological differences and bias can also all lead to variation in prevalence estimates. 
Table 1. Response rates, by demographic characteristics

\begin{tabular}{|c|c|c|c|c|c|c|}
\hline & \multirow[t]{2}{*}{ Parameter } & \multicolumn{2}{|c|}{$\begin{array}{c}\text { Enumerated } \\
(n=6713)\end{array}$} & \multicolumn{2}{|c|}{$\begin{array}{l}\text { Examined } \\
(n=5779)\end{array}$} & \multirow{2}{*}{$\begin{array}{c}\text { Response rate } \\
\%\end{array}$} \\
\hline & & $\mathrm{N}$ & $\%$ & $\mathrm{~N}$ & $\%$ & \\
\hline \multirow[t]{4}{*}{ Age groups } & $40-49$ years & 2053 & 30.6 & 1708 & 29.6 & 83.2 \\
\hline & $50-59$ years & 2178 & 32.4 & 1859 & 32.2 & 85.4 \\
\hline & $50-69$ years & 1570 & 23.4 & 1424 & 24.6 & 90.7 \\
\hline & $\geq 70$ years & 912 & 13.6 & 788 & 13.6 & 86.4 \\
\hline \multirow[t]{3}{*}{ Mean age } & Male & $56.50=$ & & $57.26=$ & & \\
\hline & Female & $56.36=$ & & $56.26=$ & & \\
\hline & Male and female & $56.42=$ & & $56.67=$ & & \\
\hline \multirow[t]{2}{*}{ Sex } & Male & 2984 & 44.4 & 2356 & 40.8 & 78.9 \\
\hline & Female & 3729 & 55.6 & 3423 & 59.2 & 91.8 \\
\hline \multirow[t]{2}{*}{ Education } & $\begin{array}{l}\text { Secondary school } \\
\text { and lower }\end{array}$ & 1935 & 28.8 & 1659 & 28.7 & 85.7 \\
\hline & $\begin{array}{l}\text { Higher than } \\
\text { Secondary school }\end{array}$ & 4778 & 71.2 & 4120 & 71.3 & 86.2 \\
\hline \multirow[t]{2}{*}{ Residence } & Rural & 5904 & 87.9 & 5102 & 86.4 & 86.3 \\
\hline & Urban & 809 & 12.1 & 677 & 11.7 & 84.5 \\
\hline \multirow[t]{2}{*}{ SES } & Lower SES & 3790 & 56.5 & 3262 & 56.4 & 86.1 \\
\hline & Higher SES & 2923 & 43.5 & 2517 & 43.5 & 86.1 \\
\hline \multirow[t]{9}{*}{ Province } & Western & 1922 & 28.6 & 1648 & 28.5 & 85.7 \\
\hline & Central & 1288 & 19.2 & 695 & 19.4 & 87.1 \\
\hline & North Western & 687 & 10.2 & 586 & 10.1 & 85.3 \\
\hline & Eastern & 582 & 8.7 & 415 & 8.6 & 85.7 \\
\hline & Northern & 555 & 8.3 & 553 & 8.1 & 84.5 \\
\hline & Sabaragamuwa & 590 & 8.8 & 510 & 8.8 & 86.4 \\
\hline & North Central & 399 & 5.9 & 346 & 6.0 & 86.7 \\
\hline & Uva & 395 & 5.9 & 348 & 6.0 & 88.1 \\
\hline & Southern & 295 & 4.4 & 678 & 4.3 & 85.1 \\
\hline Total & & 6,713 & 100.0 & 5,779 & 100.0 & 86.1 \\
\hline
\end{tabular}

Table 2. Prevalence of blindness and visual impairment (Presenting visual acuity in the better eye)

\begin{tabular}{|c|c|c|c|}
\hline Vision Category & $\begin{array}{c}\text { No. } \\
(N-5779)\end{array}$ & $\begin{array}{c}\text { Crude Prevalence \% } \\
(95 \% \text { CI })\end{array}$ & $\begin{array}{c}\text { Age-sex adjusted prevalence \% } \\
(95 \% \mathrm{CI})\end{array}$ \\
\hline \multirow[t]{2}{*}{ Normal/near normal (6/12 or better) } & 3899 & $67.5 \%$ & $68.0 \%$ \\
\hline & & $(66.3-68.7 \%)$ & $(63.4-72.6 \%)$ \\
\hline \multirow[t]{2}{*}{ Mild visual impairment $(<6 / 12-6 / 18)$} & 788 & $13.6 \%$ & $13.4 \%$ \\
\hline & & $(12.8-14.5 \%)$ & $(10.5-16.2 \%)$ \\
\hline \multirow[t]{2}{*}{ Moderate visual impairment $(<6 / 18-6 / 60)$} & 892 & $15.4 \%$ & 15.2 \\
\hline & & $(14.5-16.4 \%)$ & $(12.4-17.9 \%)$ \\
\hline Severe visual impairment $(<6 / 60)$ & 90 & $1.6 \%$ & $1.6 \%$ \\
\hline Blind $(<3 / 60)$ & & $(1.3-1.9 \%)$ & $(1.2-1.9 \%)$ \\
\hline \multirow[t]{3}{*}{ Vision could not be recorded } & 96 & $1.7 \%$ & $1.6 \%$ \\
\hline & & $(1.6-2.3 \%)$ & $(1.3-2.0 \%)$ \\
\hline & & 14 & \\
\hline
\end{tabular}


Table 3. Matrix of presenting and best-corrected vision categories, using visual acuity in the better seeing eye

\begin{tabular}{|c|c|c|c|c|c|c|c|}
\hline \multirow{3}{*}{$\begin{array}{l}\text { Presenting visual } \\
\text { acuity in better eye } \\
6 / 12 \text { or better }\end{array}$} & \multicolumn{7}{|c|}{ Best Corrected Visual Acuity in better eye } \\
\hline & \multirow{2}{*}{$\begin{array}{r}\geq 6 / 12 \\
3899\end{array}$} & \multirow{2}{*}{$\frac{<6 / 12-6 / 18}{0}$} & \multirow{2}{*}{$\frac{<6 / 18-6 / 60}{0}$} & \multirow{2}{*}{$\frac{<6 / 60-3 / 60}{0}$} & \multirow{2}{*}{$\frac{<3 / 60}{0}$} & \multicolumn{2}{|c|}{ Total } \\
\hline & & & & & & 3899 & $67.5 \%$ \\
\hline & $100 \%$ & & & & & & \\
\hline \multirow[t]{2}{*}{$<6 / 12-6 / 18$} & 686 & 102 & 0 & 0 & 0 & 788 & $13.6 \%$ \\
\hline & $87.1 \%$ & $12.9 \%$ & & & & & \\
\hline \multirow[t]{2}{*}{$<6 / 18-6 / 60$} & 493 & 184 & 215 & 0 & 0 & 892 & $15.4 \%$ \\
\hline & $55.3 \%$ & $20.6 \%$ & $24.1 \%$ & & & & \\
\hline \multirow[t]{2}{*}{$<6 / 60-3 / 60$} & 10 & 14 & 49 & 17 & 0 & 90 & $1.6 \%$ \\
\hline & $11.1 \%$ & $15.6 \%$ & $54.4 \%$ & $18.9 \%$ & & & \\
\hline \multirow[t]{2}{*}{$<3 / 60$} & 1 & 5 & 11 & 4 & 75 & 96 & $1.7 \%$ \\
\hline & $1.0 \%$ & $5.2 \%$ & $11.5 \%$ & $4.2 \%$ & $78.1 \%$ & & \\
\hline Total & 5089 & 305 & 275 & 21 & 75 & 5779 & 100 \\
\hline
\end{tabular}

Table 4. Prevalence of blindness and adjusted Odds Ratios by socio demographic characteristics

\begin{tabular}{|c|c|c|c|c|}
\hline & Variable & $\begin{array}{l}\text { Examined } \\
\mathrm{N}\end{array}$ & $\begin{array}{c}\text { Prevalence Blindness } \\
\%(\mathrm{~N})\end{array}$ & Adjusted Odds Ratio* \\
\hline \multirow[t]{5}{*}{ Age group } & $40-49$ years & 1708 & $0.2(3)$ & Ref \\
\hline & $50-59$ years & 1859 & $0.4(8)$ & $2.2(0.6-8.1)$ \\
\hline & $60-69$ years & 1424 & $1.3(19)$ & $7.3(1.6 \quad-32.5)$ \\
\hline & $\geq 70$ years & 788 & $8.4(66)$ & $132.4(11.7-149.3)$ \\
\hline & \multicolumn{4}{|c|}{$\mathrm{X}^{2}-258.7 ; \mathrm{p}<0.001$} \\
\hline \multirow[t]{3}{*}{ Sex } & Male & 2356 & $1.5(35)$ & - \\
\hline & Female & 3423 & $1.8(61)$ & - \\
\hline & \multicolumn{4}{|c|}{$\mathrm{X}^{2}-0.751 ; p=0.38$} \\
\hline \multirow[t]{10}{*}{ Province } & Uva & 348 & $2.9(10)$ & $5.3(1.3-21.5)$ \\
\hline & Eastern & 415 & $2.6(11)$ & $6.7(1.2-37.3)$ \\
\hline & North West & 586 & $2.6(15)$ & $7.3(1.8-29.0)$ \\
\hline & North & 553 & $2.2(12)$ & $12.0(2.0-71.8)$ \\
\hline & Central & 695 & 1.9 (13) & $0.8(0.07-8.9)$ \\
\hline & North Central & 346 & $1.7(6)$ & $12.5(1.5-104.6)$ \\
\hline & Sabaragamuwa & 510 & $1.4(7)$ & $3.3(0.7-14.5)$ \\
\hline & Western Province & 1648 & $1.2(20)$ & $5.3(1.2-24.4)$ \\
\hline & South & 678 & $0.3(2)$ & Ref \\
\hline & \multicolumn{4}{|c|}{$X^{2}-19.61 ; p=0.01$} \\
\hline \multirow[t]{3}{*}{ SES } & Lowest quartile & 3262 & $2.0(67)$ & $1.02(0.6-1.7)$ \\
\hline & Highest quartile & 2517 & $1.1(29)$ & Ref \\
\hline & \multicolumn{4}{|c|}{$\mathrm{X}^{2}-7.07 ; \mathrm{p}=0.008$} \\
\hline \multirow[t]{3}{*}{ Residence } & Rural & 5102 & $1.7(88)$ & - \\
\hline & Urban & 677 & $1.2(8)$ & - \\
\hline & \multicolumn{4}{|c|}{$\mathrm{X}^{2}-1.1 ; \mathrm{p}=0.3$} \\
\hline \multirow[t]{4}{*}{ Ethnic group } & Tamil & 1053 & $2.6(27)$ & $2.1(0.3-1.2)$ \\
\hline & Sinhala & 4546 & $1.5(68)$ & Ref \\
\hline & Moor & 180 & $0.6(1)$ & - \\
\hline & \multicolumn{4}{|c|}{$\mathrm{X}^{2}-7.34 ; \mathrm{p}=0.03$} \\
\hline \multirow[t]{3}{*}{ Literacy } & Secondary school and lower & 1659 & $4.0(66)$ & $2.3(1.5-3.7)$ \\
\hline & Higher than Secondary school & 4120 & $0.7(30)$ & Ref \\
\hline & \multicolumn{4}{|c|}{$\mathrm{X}^{2}-76.5 ; \mathrm{p}<0.001$} \\
\hline
\end{tabular}

* Adjusted Odds Ratio - Adjusted for age and sex 
Table 5. Causes of blindness, visual impairment and low vision

\begin{tabular}{|c|c|c|c|c|c|c|c|c|c|c|}
\hline \multirow{3}{*}{ Causes } & \multicolumn{10}{|c|}{ Category of visual loss using presenting visual acuity in the better eye } \\
\hline & \multicolumn{2}{|c|}{ Mild } & \multicolumn{2}{|c|}{ Moderate } & \multicolumn{2}{|c|}{ Severe } & \multicolumn{2}{|c|}{ Blind } & \multicolumn{2}{|c|}{ Low vision } \\
\hline & $N$ & $\%$ & $N$ & $\%$ & $N$ & $\%$ & $N$ & $\%$ & $N$ & $\%$ \\
\hline Refractive errors & 638 & 81 & 571 & 64 & 42 & 46.7 & 12 & 12.5 & 613 & 62.4 \\
\hline \multicolumn{11}{|l|}{ Lens related } \\
\hline Cataract & 62 & 7.9 & 205 & 22.9 & 33 & 36.7 & 64 & 66.7 & 238 & 24.2 \\
\hline Pseudophakia & 60 & 7.6 & 71 & 8 & 2 & 2.2 & 2 & 2.1 & 73 & 7.4 \\
\hline $\mathrm{PCO}$ & 8 & 1 & 14 & 1.6 & 5 & 5.6 & 2 & 2.1 & 19 & 1.9 \\
\hline Surgical complications & 1 & 0.1 & 2 & 0.2 & 1 & 1.1 & 2 & 2.1 & 3 & 0.3 \\
\hline Uncorrected aphakia & 8 & 1 & 7 & 0.8 & 2 & 2.2 & 0 & 0 & 9 & 0.9 \\
\hline Glaucoma & 0 & 0 & 1 & 0.1 & 0 & 0 & 2 & 2.1 & 1 & 0.1 \\
\hline \multicolumn{11}{|l|}{ Retinal disorders } \\
\hline Diabetic retinopathy & 3 & 0.4 & 3 & 0.3 & 0 & 0 & 0 & 0 & 3 & 0.3 \\
\hline Other vasculopathy & 0 & 0 & 1 & 0.1 & 0 & 0 & 0 & 0 & 1 & 0.1 \\
\hline ARMD & 2 & 0.3 & 2 & 0.2 & 2 & 2.2 & 2 & 2.1 & 4 & 0.4 \\
\hline Other retinal disorders & 1 & 0.1 & 6 & 0.7 & 0 & 0 & 5 & 5.2 & 6 & 0.6 \\
\hline \multicolumn{11}{|l|}{ Other disorders } \\
\hline Corneal opacity & 0 & 0 & 2 & 0.2 & 0 & 0 & 0 & 0 & 2 & 0.2 \\
\hline Optic atrophy & 0 & 0 & 0 & 0 & 0 & 0 & 1 & 1 & 0 & 0 \\
\hline Amblyopia & 5 & 0.6 & 7 & 0.9 & 3 & 3.3 & 1 & 1 & 10 & 1 \\
\hline Phthisis & 0 & 0 & 0 & 0 & 0 & 0 & 1 & 1 & 0 & 0 \\
\hline Could not be determined & 0 & 0 & 0 & 0 & 0 & 0 & 2 & 2.1 & 0 & 0 \\
\hline Total & 788 & 100 & 892 & 100 & 90 & 100 & 96 & 100 & 613 & 100 \\
\hline
\end{tabular}

$\mathrm{VI}=$ Visual impairment $\mathrm{PCO}=$ posterior capsule opacity; ARMD $=$ Age related macular degeneration

Globally, $60 \%$ of blindness occurs amongst females [15], reflecting the higher incidence of some conditions such as cataract, trachoma and age related macular degeneration, as well as lower access to services in some settings $[16,17]$. The finding in Sri Lanka that there were no significant gender differences suggests that there is equal access to services for males and females.

Uva Province had the highest prevalence of blindness followed by Eastern, North, North-West and Northern Province. It should be noted that Sri Lanka's Poverty Head Count Index (percentage) is also higher in these provinces [18].

All previous studies in the South and Southeast Asia regions have shown cataract to be the commonest cause of blindness, being $42.0 \%$ in the Southeast Asia region and $41.7 \%$ in the South Asia region (GBD causes) [2]. Globally, cataract was responsible for $33 \%$ of blindness in 2010, causing a higher proportion of blindness in South and Southeast Asia than in other regions [17]. We also found that cataract was the commonest cause of blindness just as the earlier study from Sri Lanka that showed that cataract $(79 \%)$ followed by ARMD were the commonest causes [3].

Cataract related complications accounted for $6.3 \%$ of blindness in Sri Lanka but none were blind from uncorrected aphakia, unlike in other countries in the region. This finding reflects the universal use of intraocular lenses (IOL) for cataract surgery since 1995. Another notable difference is that in Sri Lanka corneal blindness was not a problem, largely because trachoma does not exist due to the high levels of socioeconomic development and a subtropical climate. No participants were blind from diabetic retinopathy (DR), as reported from surveys in Bangladesh [13], and India (Andhra Pradesh) [17], but six were visually impaired from DR. The low proportion of blindness due to DR probably reflects several factors. Firstly, the epidemic of diabetes in Asia is recent, and duration of disease is a known risk factor for retinopathy. Second, poor control of blood glucose, hypertension and hyperlipidemia, known risk factors for the complications of diabetes including retinopathy [19], also increase the risk of mortality, and lastly, cataract may have masked the presence of diabetic retinopathy.

Findings from this survey can be generalized to the entire country as the sample was representative of the population of Sri Lanka in terms of age, gender, rural/urban place of residence and literacy. As in all surveys of visual impairment, the main causes at the level of the individual are reported, which means that conditions which are potentially blinding but which were not the main cause are not reported. This applies to glaucoma and diabetic retinopathy, which were infrequently documented as the main cause of visual loss. 
The survey provides valuable data for setting priorities and for national program planning, bearing in mind the anticipated increase in the size as well as the age of the population. To keep up with the anticipated increase in demand, services will need to expand, particularly for cataract [20]. There are currently 101 ophthalmologists in Sri Lanka (i.e. almost 5 per million population), 61 of whom work in the Government sector. However, eye care is not evenly distributed across the country with the Central and Western Provinces being the best served (4.1 and 3.8 ophthalmologists per million population respectively) and Sabaragamuwa, Uva and the East Province being least served $(1.5,1.5$ and 1.9 ophthalmologists/ million respectively). Eye care is provided free in Government hospitals but until recently cataract patients had the option to buy their own IOL. IOLs are now provided by the Government. Eye care in Sri Lanka has also been supported by national and international non-government organizations for many years, and there is a strong primary health care system with staff trained in primary eye care. This developed infrastructure creates opportunities for further strengthening the services with a focus on those who are particularly difficult to reach.

Interventions to reduce the prevalence of visual impairment from avoidable causes, including increasing access through human resource development and expanding infrastructure, will need to focus on provinces with the highest prevalence of vision impairment i.e., Uva, Eastern, North Eastern and Northern, and the most marginalized within the population i.e., the aged and less well educated.

\section{Acknowledgements}

We acknowledge the support from the members of the Steering Committee, the Sri Lanka College of Ophthalmologists, the Vision2020 Secretariat, Ministry of Health \& Family Welfare, Sri Lanka, Sightsavers Country Office, Sri Lanka and all the supervisors and field investigators (Madhuni Wijepala, Subhashini Deshappriya, Rasika Damayanthi, Dinusha Sandamali, Ashanti de Silva, Chaturika Madushani, Menaka Rathnayake, Madusha Priyadarshini, Nadeesha Dilhani, Gaya Shanthi) and data entry operators (Sunethra Thennakoon, Kumuduni Sriyalatha) who worked with great diligence in collecting the data from the survey participants. We thank all the survey participants for giving us the time and opportunity to interact with them to collect critical data.

We would like to thank Sightsavers for financial support of the overall study and CBM for financial contribution to the disability component of the survey.

\section{References}

1. Pascolini D, Mariotti SP. Global estimates of visual impairment: 2010. Br J Ophthalmol 2012; 96: 614-8.
2. Stevens RA, White RA, Flaxman SR, Price H, Jonas JB, Keeffe J. Global prevalence of vision impairment and blindness: magnitude and temporal trends, 1990-2010. Ophthalmology 2013; 120: 2377-84.

3. Edussuriya K, Sennanayake S, Senaratne T, et al. The prevalence and causes of visual impairment in Central Sri Lanka: The Kandy Eye Study. Ophthalmology 2009; 116: 52-6.

4. World Bank, 2008. Sri Lanka addressing the needs of an ageing population. Available at: http://siteresources. worldbank.org/INTSRILANKA/Resources/LKAging FullRep.pdf. Accessed October 212016.

5. Karunathilake IM. Health changes in Sri Lanka: Benefits of primary health care and public health. Asia Pacific J Public Health 2012; 24: 663-671.

6. World Health Organization. Universal eye health: a global action plan 2014-2019. Available at: www.who.int/ blindness/actionplan/en/. Accessed October 212016

7. World Health Organization, Geneva, 1988. Coding instructions for the WHO/PBL Eye Examination Record (Version III). WHO/PBL/88.1

8. Murthy GV, Gupta SK, Bachani D, et al. Current estimates of blindness in India. Br J Ophthalmol 2005; 89: 257-60.

9. Murthy GV, Vashist P, John N, et al. Prevalence and causes of visual impairment and blindness in older adults in an area of India with high cataract surgical rate. Ophthalmic Epidemiol 2010; 17: 185-95.

10. Jadoon MZ, Dineen B, Bourne RR, et al. Prevalence of blindness and visual impairment in Pakistan: The Pakistan National Blindness and Visual Impairment Survey. Invest Ophthalmol Vis Sic 2006; 47: 4749-55.

11. Casson RJ, Newland HS, Muecke J, et al. Prevalence and causes of visual impairment in rural Myanmar: The Meiktila Eye Study. Ophthalmology 2007; 114: 2302-8.

12. Thapa SS, Berg RV, Khanal S, et al. Prevalence of visual impairment, cataract surgery and awareness of cataract and glaucoma in Bhakapur district of Nepal. BMC Ophthalmology 2011; 11: 2 doi: 10.1186/1471-2415-11-2.

13. Dineen BP, Bourne RR, Ali SM, et al. Prevalence and causes of blindness and visual impairment in Bangladeshi adults: results of the national blindness and low vision survey in Bangladesh. Br J Ophthalmol 2003; 87: 820-8.

14. Dineen B., Foster A and Faal H. A proposed rapid methodology to assess the prevalence and causes of blindness and visual impairment. Ophthalmic Epidemiology 2006; 13: $31-4$.

15. Lewallen $S$, Courtright $P$. Gender and use of cataract surgical services in developing countries. Bull World Health Organ. 2002; 80: 300-3.

16. Gilbert CE, Shah SP, Jadoon MZ, et al and the Pakistan National Eye Survey Study Group. Poverty and blindness in Pakistan. Results from the Pakistan National Blindness survey. Brit. Med. J. 2008; 336(7634): 29-32. 
17. Dandona L, Dandona R, Srinivas M, Giridhar P, Vilas K, Prasad MN, John RK; McCarty CA; Rao GN. Blindness in the Indian State of Andhra Pradesh. Invest. Ophthalmol. Vis Sci. 2001; 42: 908-16.

18. Poverty Indicators Report 2012-2013. Department of Census and Statistics.

[Internet] Available at http://www.statistics.gov.lk/ povertyindicators2012 13.pdf. Accessed October 212016
19. Yau JW, Rogers SL, Kawasaki R, et al. Meta-Analysis for Eye Disease (META-EYE) Study Group. Global prevalence and major risk factors of diabetic retinopathy. Diabetes Care. 2012; 35(3): 556-64.

20. Murthy GVS, Gupta SK, Vashist P. Current status of cataract blindness and VISION 2020: the right to sight initiative in India. Ind. J Ophthalmol 2008; 56(6): 489-94. 